\title{
A Dominância Sônica e a Festa de Sound System de Reggae*
}

Sonic Dominance and the Reggae Sound System Session

\section{Julian Henriques}

É professor do Departamento de Mídia, Comunicação e Estudos Culturais de Goldsmiths, University of London. É artista sonoro, autor de Sonic Bodies (2011) e Sonic Media (no prelo), roteirista e diretor de cinema. Dirigiu, entre outros, os filmes Babymother (longa-metragem de 1998) e "We the Ragamuffin" (documentário curta-metragem de 1992), dentro da temática do universo dos sound systems de reggae ao qual se dedica como co-fundador do grupo de pesquisa Sound Systems Outernational.

\section{Tradução}

\section{Bernardo Girauta}

É músico e doutorando no Programa de Pós-Graduação em Comunicação e Cultura da UFRJ. Pesquisa as relações entre música, tecnologia e cosmologia através da comparação entre os conceitos de ruído e harmonia. Lançou dois álbuns solo, duas pessoas vestindo trajes formais sentadas atrás de uma bancada sobre um fundo azul (2018, Seminal Records) e CMiK ICF-10 (2020, independente), além de Fantasma (2019, Quintavant), com Gabriela Nobre.

\section{Revisão técnica \\ Liv Sovik e Maria Fantinato}

Submetido em 15 de Fevereiro de 2020 Aceito em 08 de Abril de 2020

\footnotetext{
* Este artigo é uma tradução de um capítulo de Michael BULL e Les BACK (orgs.). The Auditory Culture Reader. Oxford: Berg Publishers, 2003. Used by permission of Bloomsbury Publishing Plc.
}

Dossiê A Música e suas Determinações Materiais - https://revistaecopos.eco.ufri.br/ 


\section{RESUMO}

Este texto marca o início do interesse acadêmico de Julian Henriques pela temática dos sound systems de reggae e aponta muitos dos interesses que desenvolverá mais tarde. Inclui, então, passagens descritivas da cena do reggae no estilo dancehall na Jamaica de duas décadas atrás, focalizando os engenheiros de som que constroem e operam as aparelhagens; considerações sobre o sonoro em relação a outros estímulos sensórios, sobretudo visuais; música e som; o conceito de "dominância sônica", que propõe para descrever a presença forte do som em festas, bailes ou "sessões" de reggae; e a relação desta com o corpo do público.

PALAVRAS-CHAVE: Sound systems; reggae; som e os sentidos; corporificação; estudos culturais.

\section{ABSTRACT}

This article marks the beginning of Julian Henriques' academic research on reggae sound systems and points to many of the interests that he develops in later research. It discusses dancehall reggae scene in Jamaica at the beginning of the $21^{\text {st }}$ century and the sound engineers who build and operate sound systems. It considers sound in relation to other sensory stimuli, especially visual ones; and music and sound in the context of reggae sound system sessions. Finally, it proposes the concept of "sonic dominance" and the relationship of this quality of sound to the crowd's embodiment.

KEYWORDS: Reggae sound systems; sound and the senses; embodiment; cultural studies.

O som conecta as pessoas; ele nos une. ${ }^{1}$ Foi Count Basie que me aproximou de um dos editores desse volume. Ele estava tocando Lester Leaps In. E foi o som da música que me puxou por uma porta entreaberta. Ali, na frente de uma sala de aula vazia, um velho gramofone a manivela de 78 rotações. Les Back estava preparando uma palestra sobre o jazz na Alemanha do pré-guerra. Nós não nos conhecíamos, mas rapidamente começamos a falar sobre interesses mútuos de pesquisa...

Este texto propõe possibilidades para o entendimento de alguns efeitos e afetos do som e a natureza e as qualidades do sônico. ${ }^{2}$ Para isso, eu identifico um fenômeno particular que chamo de dominância sônica. Torcidas de futebol, festas rave, ${ }^{3}$ passeatas políticas e certos rituais religiosos são outros contextos que 
produzem esse fenômeno de dominância sônica. Mas meu local preferido para a experiência da dominância sônica é a festa de sound system de reggae. ${ }^{i}$ Para mim, esse é o exemplo epistêmico. ${ }^{4}$

A primeira coisa que lhe atinge em uma festa de sound system de reggae é o som em si. Sua enorme força física, volume, peso e massa. A dominância sônica é dura, extrema e excessiva. Ao mesmo tempo, o som é também macio e acolhedor, criando uma experiência intensa, imersiva e envolvente. 0 som permeia, ou mesmo invade o corpo, como um cheiro. A dominância sônica é, ao mesmo tempo, uma quase sobre-carga de som e uma super saturação do som. Você está perdido dentro dele, submerso nele. Esse volume de som quebra sobre você como uma onda do mar, você sente a pressão do peso do ar como se estivesse mergulhando fundo debaixo d'água. Não há escapatória, interrupção ou escolha a não ser estar ali. Ainda mais do que música escutada normalmente nesse volume, o som nos permite bloquear nossos processos racionais, tornando a experiência iminente, imediata e não-mediada. Mas quanto mais poderosa e irrepetível é a experiência, mais se torna impossível descrevê-la na sua totalidade - e, paradoxalmente, mais ela demanda ser alvo de gestos, apontada, discutida e interminavelmente elaborada em todos os seus efeitos e afetos. A dominância sônica é visceral, como carne e osso. 0 som nesse volume não pode senão tocá-lo e conectá-lo ao seu corpo. Ele é não somente escutado com os ouvidos, mas sentido por toda a superfície da pele. As linhas de baixo pulsam em seu peito, vibrando a carne, tocando os ossos e ressoando as genitais.

A dominância sônica ocorre quando e onde o meio sônico desloca a dominância usual ou normal do meio visual. Com a dominância sônica, o som quase monopoliza a atenção. A modalidade sensorial aural se torna $a$ modalidade

\footnotetext{
i Na cena musical brasileira, geralmente se usa a expressão em inglês "sound system" para se referir às grandes aparelhagens de som em que se toca reggae, distinguindo-as dos "sistemas de som" usados no dub, no funk carioca e no reggae de Portugal, e da "aparelhagem", do tecnobrega. Aqui, usa-se "festa" para denotar o evento em que se usa o sound system, embora "sessão", semelhante a "session", também circule. Finalmente, para traduzir "crowd", optou-se, em geral, por "galera", pois a tradução literal, "multidão", já adquiriu outros sentidos nas ciências sociais. (N.T.)
} 
sensorial em vez de uma entre as outras como ver, cheirar, tocar e saborear. Essa dominância do sônico sempre pode, é claro, ser interrompida, por exemplo, ao se sentir cheiro de fogo ou ver uma arma ou uma faca. É apenas com transes religiosos profundos que, por exemplo, a sensação de dor pode ser completamente bloqueada.

A relação entre os diferentes sentidos, e o modo como os sentidos são organizados hierarquicamente e não-hierarquicamente, é o tema central deste texto. ${ }^{5}$ Com o sônico, como pretendo discutir, o ambiente, o contexto e a combinação dos sentidos são todos particularmente vitais. Uma complicação adicional é que, em relação à importância relativa dos sentidos, a prática do dia a dia das pessoas é usualmente diferente de seus próprios entendimentos acerca de o que é que elas estão fazendo. Essa é uma questão que Pierre Bourdieu levanta: "É porque os sujeitos, estritamente falando, não sabem o que eles estão fazendo, que o que eles fazem tem mais sentido do que aquilo que eles sabem" (Bourdieu, 1977). E, por sua vez, o próprio entendimento de uma pessoa pode ser diferente de como a teoria filosófica e social considera a importância relativa dos sentidos.

Falando de modo geral, o mundo sônico e aural é provavelmente mais importante e útil para a compreensão da vida e a negociação do mundo do dia a dia do que as pessoas podem pensar. Na prática, é a cooperação entre os sentidos que é normalmente mais importante do que qualquer hierarquia rígida. Por contraste, o impulso de grande parte da tradição ocidental, filosófica e das ciências sociais ocidental, é de privilegiar o sentido visual como fonte do conhecimento sobre todos os outros. Uma das ambições do presente texto, e do projeto do qual ele faz parte, é que a teoria reconheça aquilo que já está incorporado na prática acerca do sônico - a despeito da lembrança do poeta W.B. Yeats: "o homem pode incorporar a verdade, mas ele não pode conhecê-la" apud Levin (1985, p.30).

Eu escolhi a palavra 'dominância' deliberadamente para sugerir tanto o poder como o prazer do sônico. Isso exige uma distinção entre dois diferentes aspectos do poder. Normalmente, o poder é considerado como possuído e usado

Dossiê A Música e suas Determinações Materiais - https://revistaecopos.eco.ufri.br/ 
sobre outros, como opressão ou subjugação. Contudo, o poder pode também ser considerado como compartilhado com outros, como em esforços coletivos pacíficos. É dessa capacidade criativa e poder produtivo da multidão - como Hardt e Negri teorizam - que o Império se alimenta (Hardt e Negri, 2000, p.103). A dominância sônica é importante nesse segundo sentido, como força de vida. Outro dos temas a serem desenvolvidos aqui é o modo como o sônico sugere um entendimento baseado em conexão, combinação e síntese, em vez de apenas em divisão, separação ou análise. Na festa de sound system, o som é dominante. Mas é também irresistível. Bob Marley estava obviamente pensando no sound system quando cantou: "A melhor coisa da música/Quando ela acerta você não sente dor" [The one good thing about music/When it hits you feel no pain]. 0 que você sente é prazer, ou algo que mesmo resiste à mercantilização - alegria. ${ }^{6}$

A galera do dancehall participa da festa, como aqueles que participam do desfile de carnaval em Port of Spain, Trinidad, ou em Notting Hill, Londres, pelos prazeres da experiência. Eles curtem o sentimento de que estão "tomando o controle", sendo "donos da rua" e assumindo seu próprio valor, importância e identidade na "rua feita para andar no Dia do Carnaval" (Howe, 1977). E o som cumpre um grande papel nisso. É como se o som em si se tornasse tanto uma fonte como uma expressão desse poder. Mas, como é de se esperar do entendimento contextual e relacional sendo desenvolvido, os efeitos e os afetos da dominância sônica não são necessariamente e previsivelmente uma única coisa. Esse é um tipo de poder que pode ser usado para o bem e para o mal. Como o som é usado depende das convenções e tradições sociais, políticas e culturais específicas. E, também, a liderança da galera é uma questão crítica. 0 público no Coliseu na Roma Antiga, ou algumas torcidas de futebol, ou um comício nazista demonstram como a dominância sônica pode ser usada negativamente e destrutivamente. A dominância sônica carrega esse limiar de risco, ou até mesmo de abandono. Como afirma o DJ da minha estação de rádio pirata local Charlie $\mathrm{B}$, na Vibes FM: "Sintonize, aumente o volume e arranque o botão. A gente não está nem aí".

Dossiê A Música e suas Determinações Materiais - https://revistaecopos.eco.ufri.br/ 


\section{o Sound System de Reggae}

O reggae sound system é considerado aqui como um laboratório vivo já existente, constituído social e culturalmente. ${ }^{7}$ Esse modelo ou aparato técnico será usado para a demonstração e investigação do fenômeno da dominância sônica. ${ }^{8} 0$ sound system de reggae tem seu lugar em uma paisagem aural, oral, acústica, auditória e musical que é extremamente rica e variada. E na Jamaica há outras instituições nas quais o sônico é usado de modo similar ao do sound system, a saber, as inúmeras igrejas batistas locais e as formas religiosas jamaicanas de matriz africana, como Kumina, Myal e Pocomania. ${ }^{9} 10$

De todos os sound systems, o mais conhecido, antigo e renomado por todo o mundo é o Stone Love. Fundado por Mr. Winston "Wee Pow" Powell, Stone Love possui vários conjuntos de equipamentos que, junto com suas equipes, trabalham continuamente. Um deles é baseado em Kingston, outro atende ao resto da Jamaica e o terceiro fica mais ou menos permanentemente em turnê mundial. O Stone Love ajudou a promover o reggae na América do Norte, Europa e Japão. Em casa, Mr. Powell tem ainda usado o apelo de sua música para ajudar a colmatar algumas das divisões políticas e de classe da ilha. Viajando de show em show como um circo, o sound system pode ser descrito como uma instituição nomádica circulante, peripatética e altamente móvel (Braidotti, 1994; Deleuze e Guattari, 1988). 0 sound system é inseparável do movimento não apenas através do tempo, mas também através do espaço.

Para seus seguidores e fãs, Stone Love defendeu com sucesso a sua posição no topo da tabela da liga dos sound systems pelos últimos 30 anos. Em "clashes" competitivos especiais entre sistemas de som eles têm vencido consistentemente seus sistemas rivais pelo apoio da galera. Isso ocorre através do poder e da qualidade do som, da escolha musical do seletorii, e dos "dubplates ${ }^{\mathrm{iii}}$ especiais"

\footnotetext{
ii Nome que se dá ao DJ na Jamaica. (N.T).
} 
raros que tenham sido exclusivamente comissionados a eles pelos principais artistas de gravação do momento.

Tecnologicamente, um sound system de reggae é um aparato móvel para a produção e mixagem de grandes volumes de som. Ele consiste no "conjunto" ou set, isto é, o equipamento de amplificação capaz de produzir algo como 19.000 watts de som bem mixado (como me contou Horace McNeal, o Engenheiro Chefe e Construtor de Alto-Falantes do Stone Love). Os outros componentes principais do set são as "paredões" de caixas de som. Normalmente, três pilhas de caixas são usadas em uma configuração triangular que aponta para dentro da "galera do dancehall", em vez de direcionadas para fora sobre uma audiência, como ocorreria se elas estivessem posicionadas dos dois lados de um palco. A sessão de sound system cria uma bacia, um receptáculo, ou um anfiteatro que é inteiramente preenchido com o som e a galera, mas aberto em direção ao céu.

Sound systems são microcosmos das relações sônicas sociais, culturais e econômicas das quais eles participam. Eles são uma forma de expressão que vem das áreas centrais de West Kingston. Nos anos 1960, Prince Buster chamou seu sound system mais popular de Voice of the People. Eles também constituem uma forma de entretenimento que é parte da criatividade das culturas do reggae e do dancehall. Apenas recentemente passaram a existir sistemas de som que são propriedade da classe média. Apenas nos últimos cerca de dez anos o Stone Love tocou em clubes e bairros de uma nova audiência de classe média. Como a própria música reggae, que absorve outras influências musicais, a aparelhagem de som é suficientemente robusta para absorver todos que chegam - misturando e combinando para se fortalecer em vez de se enfraquecer.

Ao longo dos últimos 40 anos, sound systems de reggae na Jamaica se tornaram instituições equivalentes às igrejas locais e aos times de futebol. Eles também inspiram lealdade e fervor de maneira similar. Empregam um grande

iii Dubplates são LPs gravados em sistema artesanal, tocados em pré-lançamento em clubes, antes das músicas estarem disponíveis para venda. (N.T.)

Dossiê A Música e suas Determinações Materiais - https://revistaecopos.eco.ufri.br/ 
número de pessoas e influenciam diretamente as vidas de muitas outras, de vendedores de amendoim a políticos que os utilizam para atrair as massas para seus encontros. Os sound systems também tiveram uma influência considerável no desenvolvimento da música reggae. 0 atual dancehall reggae tem esse nome porque, por ter sido banido do rádio, só podia ser ouvido nos dancehalls ou salões de baile a céu aberto, em sound systems.

Isso nos leva ao interior da arena política, à linha de batalha na qual o som e, particularmente, a dominância sônica está invariavelmente envolvida. Na sociedade jamaicana, que é altamente polarizada e uma mistura imensamente complexa de cor, classe e casta, ${ }^{11}$ a cultura dancehall cumpre frequentemente o papel de fronteira entre a classe pobre e trabalhadora e a classe média jamaicanas. Apesar de a música reggae ser reconhecida como aquilo que dá à Jamaica seu perfil global, somente a juventude, entre a classe média, consegue ouvir algo de valioso na música contemporânea. É importante notar que a crítica ao sound system e sua cultura é expressada como crítica aos prazeres do corpo e do corpo feminino em particular.

A geração mais velha das classes médias jamaicanas considera o dancehall o estilo e a atitude, as danças despudoradas, a moda imodesta, os cabelos e maquiagens extravagantes - inteira e absolutamente excessivo. Para eles, as letras promovem apenas violência e moleza ou "slackness", como se diz na Jamaica. (Se o Corpo Mau é solto, relaxado e frouxo, então, presumivelmente, o Corpo Bom deve ser tenso, correto e reprimido.) Chamados à censura e ao banimento do dancehall são comuns nas colunas de opinião dos jornais. Restrições e regulações são discutidos nos inúmeros talk shows de rádio, que por sua vez são um aspecto particular da paisagem midiática jamaicana (em ressonância com a forte cultura oral da Jamaica). Para as classes médias ultrajadas, o dancehall está simplesmente fora de controle. De fato, ele floresce a partir de uma criatividade e uma imaginação fundadas na extravagância, fluxos livres, excesso, excedentes e em uma economia do prazer (ver Hardt e Negri, 1994; e Bataille, 1988). Isso vai de 
encontro a costumes convencionais da classe média de uma ilha que é uma excolônia e, do ponto de vista da metrópole, parece particularmente empertigada e marcadamente antiquada. Nesse sentido, as atitudes tendem a se conformar a modelos de desejo psicodinâmicos convencionais. Em geral, elas podem ser caracterizadas como motivadas por medo, insuficiência e falta - o exato oposto do excedente.

0 modo pelo qual o sound system toca sua música é também considerado excessivamente alto. Isso é, evidentemente, o tipo de avaliação que coloca o sound system em meio às controvérsias acerca de sua regulamentação. Essa dinâmica de expressão e repressão, prazer e retenção, amplificação e filtragem, é frequentemente um aspecto crítico do sônico. ${ }^{12}$ A Lei de Redução do Ruído [Noise Abatement Act], de 1996, tentou restringir o volume e o número de vezes que os sistemas de som estão autorizados a tocar. Ele afirma, na sua Seção 7: "o nível de ruído na Jamaica, tanto de dia quanto à noite, se tornou realmente espantoso, e está afetando a saúde e o bem-estar da nação." Como consequência do debate acerca dessa suposta poluição sonora, a Sound System Association of Jamaica se formou. Seu propósito, como me contou a co-fundadora e assessora de imprensa da Associação, Louise Frazer-Bennett, era lutar contra o que ela enxerga como restrições às suas liberdades e defender a música como a forma chave de expressão cultural para as comunidades pobres e trabalhadoras da Jamaica.

Para os cidadãos da classe média jamaicana, os excessos aparentemente incontroláveis e a natureza social do sônico fizeram com que ele fosse considerado perigoso ao status quo. Na teoria social, apenas a tradição marxista valoriza a solidariedade, a sociabilidade e as relações sociais, em quaisquer casos. Fora isso, a natureza social do ser costuma ser teorizada como inferior, desprovida de racionalidade e ameaçadora ao indivíduo. A massa, particularmente, deve ser temida, como foi detalhado em $A$ Multidão: um estudo da mente popular, de Gustave Le Bon, publicado em 1900. E Jacques Attali (1985), em sua obra intitulado "Ruídos", identifica uma das razões por que essa associação entre o 
sônico e o social é considerada perigosa. Ele reivindica que formas musicais podem antecipar formas sociais. Certamente, subculturas jovens contemporâneas invariavelmente usam o som musical, possivelmente mais que a imagem visual, como seu ponto de identificação, quando não de rebelião. De fato, uma característica importante da cultura do sound system é que ela fornece uma tradição que prescreve limites de tempo e espaço para tal sociabilidade, prevenindo-a de se tornar excessiva "demais". A descrição de Bakhtin do carnaval europeu "virando o mundo de cabeça pra baixo" ou a "efervescência coletiva" de Durkheim são precisamente exceções que confirmam a regra. A continuidade entre o carnaval e os sound systems de reggae evidencia o valor político de tais válvulas de escape como licenças temporárias para a transgressão.

Esses medos do corpo como uma ameaça à racionalidade são profundamente sentidos e remetem a um longo caminho na tradição filosófica ocidental. E na medida em que o som é conectado ao corpo, ele o alimenta. Em $O$ Nascimento da Tragédia, Nietzsche localiza o momento de origem desse fenômeno na cultura ocidental no conflito entre Apolo e Dionísio na mitologia grega antiga. A vitória de Apolo e o controle racional sobre o excesso emocional báquico de Dionísio é o tema oculto da obra-prima renascentista de Ticiano, $O$ Esfacelamento de Marsias. Aqui, a punição sofrida pelo pobre sátiro, de ter sua pele arrancada de seu corpo - literalmente, uma desincorporação -, ocorre por ele ter ousado competir com Apolo em uma competição musical. Trata-se de uma lição de disciplina racional. 0 corpo fora do controle racional é entendido como sujeito a todos os tipos de excessos perigosos associados à intoxicação, ao devaneio e ao sublime.

A dominância sônica nos leva à barreira sônica - isto é, à borda do som. A amplificação eletrônica empurra o sônico aos limites. De um lado está a música, do outro o ruído. De um lado está a regulação, as modulações e a moderação, do outro está a irregularidade, a imprevisibilidade e o excesso. 0 ruído perturba, desloca e interrompe a chamada harmonia do status quo. ${ }^{13} 0$ ruído não é sinal, não é música, 
não é organizado, não é normal e não está sob controle. Ele quebra as regras sociais prescritas. O ruído é "rude e boçal", "estranho" e "selvagem" - as palavras usadas pelo cirurgião de um navio para descrever os escravos utilizados para cantar e dançar em suas travessias. ${ }^{14} \mathrm{O}$ ruído deixa o som fora de ordem. É caos. E isso, é claro, é sua criatividade, e isso é igualmente obviamente necessário para o crescimento contínuo do corpo social e político como um todo. Com a dominância sônica, o sound system de reggae está explorando um limiar parecido entre o ruído e a música que, no início do século XX, se mostrou tão produtiva para a tradição ocidental do modernismo. O futurista Luigi Russolo fez “máquinas de ruído" e publicou A Arte do Ruído em 1913 (ver Kahn, 1999). O ruído vem de fora do sistema teórico a partir dos pedaços intermediários, intervalos, lacunas, dobras e interstícios (ver Deleuze, 1986 e 1993; Deleuze e Guattari, 1988). A dominância sônica vem de fora do sistema social da classe média suburbana, parte das margens abandonadas da sociedade, isto é, dos guetos do centro de West Kingston.

\section{A intensidade e a materialidade do som}

O som simplesmente bate em você. Você não pode ignorá-lo. Você tem que senti-lo. Ao descrever a festa do sound system de reggae com a palavra "dominância", a intenção é de sugerir a substância material e a iminência do som. Os efeitos e afetos da intensidade ou sobrecarga de som podem ser comparados à extrema "subcarga" [underload] que é produzida no silêncio absoluto das câmaras anecóicas, em técnicas de meditação que utilizam uma imagem, na repetição de um mantra sonoro, e em condições experimentais de privação sensorial ${ }^{15}$. Tais estados de limiares extremamente baixos quebram a norma das quantidades modestas de estímulos sensoriais. Na privação sensorial, alucinações são comuns e, instrutivamente, elas tendem a ser experiências fora do corpo. Com a sobrecarga sensorial, ocorre o oposto, e as experiências tendem a ser de aterramento, de interiorar-se no corpo e se expressam em movimento e dança. Sobrecarga e subcarga tendem ambas a circundar o processo racional normal ${ }^{16}$. 
Quando o sound system de reggae é considerado um aparato experimental para produzir as condições para a dominância sônica, somos levados de volta à fundação da psicologia científica, no século XIX. Em 1860, Gustav Fechner publicou Elementos de Psicofísica, onde ele descreveu sua mensuração experimental da sensação e a fisiologia dos sentidos (Fechner, 1966). A preocupação de Fechner era de estabelecer uma relação quantitativa entre mente e corpo, isto é, entre sensação mental e estímulo material ${ }^{17}$. Ele investigou a sensibilidade mínima do sistema sensorial no menor limiar possível de audibilidade, visibilidade e sensação tátil. Para isso, ele desenvolveu a metodologia da diferença apenas notável [just noticeable difference] (JND) como a unidade básica de mensuração da intensidade da sensação. Por contraste, a dominância sônica ocorre no limiar superior da sensibilidade do sistema sensorial auditivo. Ela pode ser descrita em termos de diferença mal suportável [just bearable difference] (JBD) como uma reflexão anversa da fundação da ciência da psicologia.

Essa ideia de excesso como dor, provação e mesmo abuso - e também como prazer - faz parte do mundo que produziu o sound system de reggae e a cultura dancehall. Na linguagem jamaicana, um dos termos usados para expressar essa ideia é sufferation, diferente de sofrimento, ou "suffering"18. E essa atitude também se estende aos equipamentos técnicos. Discutindo o design de suas caixas de som, Horace McNeal, o engenheiro da radiola Stone Love afirmou: "nós abusamos das coisas na Jamaica, nós abusamos do equipamento musical, aquilo pro que o homem faz as coisas, a gente tá na frente."19

A dominância sônica gerada na festa de sound system de reggae chama atenção para as nossas conexões íntimas e múltiplas não apenas com o nosso corpo, mas também com os nossos ambientes espaciais e temporais. Um modo pelo qual isso foi descrito foi na fenomenologia de Merleau-Ponty. Referindo-se à nossa relação com o mundo, Merleau-Ponty emprega o termo "quiasma", que em fisiologia significa a interconexão ou entrecruzamento de nervos (Merleau-Ponty,

Dossiê A Música e suas Determinações Materiais - https://revistaecopos.eco.ufri.br/ 
1962; Weate, 2003). Isso contrasta com a suposição visual normal do abismo entre observador e observado. 0 sônico opera com as qualidades de humor, cor, textura, timbre e afeto, em vez das quantidades mensuráveis. A espacialidade específica ligada ao sônico foi descrita como "espaço acústico" (Williams, 1955)²0. Esse é um tipo de espaço em que você está tanto dentro como fora, e que está dentro de você, assim como você está dentro dele. ${ }^{21}$ De fato, simplesmente não faz sentido pensar em ter um interior e um exterior do som no mesmo sentido em que a modalidade sensorial visual, com suas preocupações com as superfícies, coloca limites. 0 som é superfície e profundidade ao mesmo tempo. Conforme a dominância sônica demonstra, o som está em todo lugar e mal faz a divisão dualista entre aqui e ali.

De fato, a dominância sônica ajuda a gerar um sentido particular específico de lugar em vez de uma ideia abstrata geral de espaço. ${ }^{22}$ Ela é única, imediata e lugar de tradição e performance ritual. Com efeito, a festa do sound system de reggae se inspira em uma rica gama de cerimônias religiosas creolizadas da África Ocidental que continuam a ser praticadas na Jamaica hoje. 0 lugar acústico e o lugar sonoro são as antíteses dos "não-lugares" tipicamente pós-modernos como os aeroportos, shopping centers, avenidas e caixas-eletrônicos discutidos por Marc Augé (Augé and Howe, 1995). Esses são espaços genéricos vazios e abstratos. Espaços sônicos são, por contraste, específicos, particulares e totalmente impregnados com a tradição viva do momento. Cada um tem uma dada hecceidade ou "qualidade de ser isto". 23

Considerando o tempo, a dominância sônica contribui para a geração de um sentido específico de evento. Trata-se do cíclico, embora irrepetível, lugar do ritual recorrente, em vez da noção abstrata de tempo contínuo ou da ideia de progresso. O tempo sônico, como o espaço sônico, não é percorrido em linhas retas. Ele é muito heterogêneo para isso. Se fosse escrito, o seria em camadas e com as profundidades de um palimpsesto. Por outro lado, a escrita do espaço visual é em planos e linhas retas euclidianas no espaço branco e uniforme de uma tabula rasa. 
Essas qualidades do espaço e do tempo, associadas com a dominância sônica, fazem dela uma experiência multi-dimensional e multi-temporal, como o espaço e o tempo fílmicos. ${ }^{24}$ Por contraste, a modalidade visual tende a ser vista como separadora e isolante, de modo mais notável na ideia de ponto de vista único. Essa ideia de perspectiva linear é bastante moderna (Ivins, 1938 e 1975; Latour, 1990). Antes da invenção renascentista da perspectiva, o espaço era retratado de um modo que parece, aos nossos olhos modernos, mais "misturado", como, por exemplo, no trabalho de Bruegel e na maior parte da pintura medieval. Outro modo de colocar este problema poderia ser considerar tais telas como um tipo acústico de representação visual (Romanyshyn, 1989). Inspirado, segundo muitas interpretações, por formas antigas e "primitivas", o renascimento do modernismo no início do último século explodiu o ponto de vista único e a imagem do tempo linear com as complexidades da perspectiva múltipla e do espaço/tempo. Nós podemos identificar isso nos "volumes" das esculturas de Picasso inspiradas pela África; nas telas cubistas fraturadas de Braque; no Homem com a Câmera e sua visão total, de Dziga Vertov; na obsessão dos poetas simbolistas com a ideia de "simultaneidade"; e até mesmo na teoria da relatividade de Einstein.

\section{Etéreo e o Material Combinados}

Mas há, é claro, o outro lado do som além de sua materialidade. As massas atendem às festas de dancehall sound systems não apenas pela qualidade do som, mas também pela música que se toca: os últimos ritmos, a recuperação de clássicos do passado e os "especiais" lançados pelos artistas mais populares do momento. De fato, a riqueza musical e a complexidade rítmica no interior da atual versão dancehall da música reggae é provavelmente maior do que em qualquer período até agora. ${ }^{25}$ Com um sound system de primeira classe, como o Stone Love, há maciez, redondeza e fartura na mixagem. Um operador de áudio jamaicano chamaria isso de um som "despojado" que possui "quique".

Dossiê A Música e suas Determinações Materiais - $\underline{\text { https://revistaecopos.eco.ufri.br/ }}$ 
Portanto, enquanto a dominância sônica infla a materialidade do som, ela não nega suas qualidades etéreas. Essas são a forma, a estrutura ou o padrão pelo qual o som foi analisado e compreendido na tradição musical ocidental. Pitágoras foi possivelmente o primeiro a considerar esse aspecto do som quando afirmou que ouvia a música das esferas. De fato, aproximar-se do som a partir de seu aspecto material permite a inclusão de seu aspecto etéreo em uma dimensão maior do que uma aproximação pelo caminho oposto. (Do mesmo modo, veremos na próxima seção que a dominância sônica inclui mais a dimensão visual do que o faz a dominância visual em relação à dimensão sonora.)

Na festa de sound system de reggae, o aural é um meio para códigos de comunicação orais e verbais, assim como uma coisa material em si. Você sente tanto o ar como o meio líquido gasoso que "carrega" o som como também escuta a forma de onda dos contornos do som. Trata-se do som como, simultaneamente, conteúdo e forma, energia acústica e informação de sinal de onda, substância e código, partícula e padrão. Isso ilustra como a conjunção ambos/e [both/and], mais do que a separação ou/ou [either/or], parece particularmente apropriada para pensar com e sobre o som. Como já foi notado, o som pode frequentemente ser caracterizado como produtor de conexões, combinações e de ser inclusivo, do mesmo modo em que a modalidade sensorial visual tende a fazer o oposto, separando as coisas. 0 músico e teórico Anthony Moore cunhou a expressão "um ou outro e ambos" [either and both] para isso. ${ }^{26}$

Essa combinação e relação entre o material e o etéreo é de importância fundamental, assim como sua distinção. Um é necessário ao outro naquilo que poderia ser descrito por meio de arquétipos, como feminino e masculino, ou terra e céu, ou yin e yang. Ambos precisam ser fortes. De fato, a sociedade jamaicana, e a cultura dancehall em particular, valorizam tanto a agressão de um homem "macho" como a fertilidade e beleza femininas. A festa de sound system de reggae fornece a arena para uma sexualidade altamente carregada.

Dossiê A Música e suas Determinações Materiais - https://revistaecopos.eco.ufri.br/ 
Essa relação de "também e ambos" entre as duas faces do som, na macroescala normal da escuta humana, pode também ser considerada análoga ao comportamento da luz na escala subatômica da mecânica quântica. Segundo o princípio da incerteza de Heisenberg, os quanta de luz se comportam tanto como onda, ou energia, quanto como uma partícula, ou matéria - ambos ao mesmo tempo. Esse caráter duplo que o som possui, de ser duas coisas ao mesmo tempo, pode não estar de acordo com noções ocidentais de racionalidade - mas é uma característica comum das festas de sound systems de reggae em vários outros aspectos a serem discutidos.

A materialidade do som é como a sensação de toque que nos conecta com nossos corpos e com o mundo pela "hecceidade" da experiência mencionada acima. Ao mesmo tempo, novamente como o toque, o som possui este outro aspecto oposto que nos separa de nós mesmos, dos outros e do mundo. 0 sonoro é tanto corporificante, quanto descorporificante. Assim como o sentido tátil é preeminente na determinação da conexão e da separação simultâneas do organismo com o seu ambiente (Soesman, 1990), o sentido sônico cumpre um papel combinatório e separatório semelhante.

Historicamente, o aspecto descorporificante do som, mais do que o corporificante, foi capturado em primeiro lugar pela tecnologia e pela imaginação popular com a invenção em 1877, por Thomas Edison, do fonógrafo. Em seu Gramophone, Film, Typewriter, Friedrich Kittler (1999) fornece uma explicação fascinante de como o primeiro uso da gravação fonográfica da voz foi o de escutar as vozes literalmente descorporificadas dos mortos. ${ }^{27}$ Esse mesmo tema foi abordado também no filme Orfeu, de Jean Cocteau, no qual o herói escuta as instruções dos mortos em transmissões de rádio. Portanto, uma vez que se tornou tecnicamente possível gravar e transmitir sons, por que pensou-se que o som seria capaz de fazer essa conexão que colmataria o abismo entre vida e morte? Talvez seja, novamente, por causa da hecceidade que ele evoca. 0 sônico nos ajuda a ter 
nossa individualidade específica. As vozes das pessoas, como seus gestos corporais, postura ou passada, são únicas como suas impressões digitais ou retinianas, ou ainda como as listras de um tigre ou as pintas de um leopardo. Esse é um aspecto da materialidade do som ao qual Roland Barthes se refere em 0 Grão da Voz (1977). A mágica fascinante dos primeiros fonógrafos é o mesmo tipo de efeito que antropólogos descrevem como sendo experienciado por membros de sociedades iletradas quando eles escutam a leitura de um livro pela primeira vez.

O ponto crítico a ser notado aqui é: somente porque a voz já foi corporificada é que ela pode ser subsequentemente descorporificada. Portanto, Nipper, o cachorro, quando escuta com tanta atenção no famoso logotipo da marca HMV, está ouvindo não só o som etéreo da voz de seu dono, mas também lembrando da autoridade incorporada nele.

A teoria da comunicação, conjuntamente com a tecnologia e a compreensão científica do fenômeno acústico, também tende a abordar o sônico exclusivamente em seu aspecto etéreo e descorporificado. Ela tende a esquecer o outro aspecto de incorporação material do som, assim como a cultura escrita tende a desprezar - e desrespeitar - as qualidades da cultura oral que ela suplanta. A ruptura feita pela vertente da teoria da informação iniciada por Claude Shannon em 1937 era considerar a informação matematicamente, isto é, como uma mensagem de sinal puramente digital sem o ruído, a interferência, a sujeira e outras matérias marginais pertencentes ao corpo analógico do meio que geralmente o cerca. Quando sampleada e convertida em informação puramente digital, o computador pode então armazenar, manipular, reproduzir e transmiti-la ad infinitum - sem o decaimento e o atraso que dificultam as modulações analógicas. Somente no ponto final de consumo é que esse código digital puramente transparente precisa ser convertido de volta em amplitudes analógicas - as únicas que os sentidos do animal humano podem apreciar. 
Mas enquanto as tecnologias de áudio e vídeo digitais são eficientes e convenientes, frequentemente sente-se que há algo faltando. Invariavelmente, esse "algo" é difícil de ser descrito (Henriques, 2002). Extrapolando a produção de dominância sônica da festa de sound system de reggae, pode-se sugerir que essa qualidade difícil-de-definir, ausente no digital, tem a ver com os prazeres sensuais corporais ligadas à materialidade do sônico. Existem três. Um é o prazer de lembrar - nostalgia. Certamente, o estalo e o ruído de superfície de um LP de vinil têm seu próprio encantamento - esse termo remete ao antigo poder da música que fez com que Odisseu encerasse seus ouvidos contra o canto das sereias. 0 grão do filme, com sua vibração através da lente do projetor, tem essas associações também. Trata-se talvez do acendimento da velha chama de um prazer passado, uma lembrança corpórea. Talvez, se comparada à sua fria e clínica contraparte digital, a quentura e a textura da reprodução analógica tenham que ser apreciadas simpaticamente como indícios da saudade corporal do próprio meio, uma nostalgia - de sua própria fonte.

Um segundo tipo de prazer da materialidade do meio tem a ver com o tipo de ambiguidade associada ao "um ou outro e ambos" de meio e mensagem, de ruído e sinal. Um exemplo disso é o golpe de pincel de um aquarelista habilidoso. Os grupos de pelos de um pincel molhado apenas pela metade podem, por exemplo, ser facilmente usados para retratar tufos de mato, quer dizer, para explorar a natureza material do meio na produção da mensagem. 0 trabalho das pinceladas a óleo de Lucien Freud é outro exemplo. De perto, em uma microescala, seus autorretratos são manchas de tinta confusas e sem sentido. Mas a uma distância apropriada à visão, uma imagem com profundidade e detalhes ricos emerge milagrosamente. É como se, como seres sensíveis, nós gostássemos de completar a pintura nós mesmos, fazer nossas próprias formas de Gestalt a partir do material, alcançar o prazer do encerramento por nós mesmos. Esse é o prazer da participação, evidente para qualquer bom contador de histórias. Um outro 
ponto é que meio e mensagem estão sempre intimamente conectados. Um exemplo disso, descrito por David Rodowick, é como a nova tecnologia de projeção digital de cinema que é feita para substituir a projeção de filmes "favoreça" ou "pareça adequada para" "filmes" digitalmente orientados, como Shrek, em vez de filmes gravados em celuloide. ${ }^{28}$

O terceiro tipo de prazer é a pura sensação. Isso é intraduzível, irredutível e um fim em si mesmo. Especialmente quando o som é a modalidade sensorial dominante, ele se torna pura experiência sensorial. 0 estudo dos afetos foi durante muito tempo uma área negligenciada da psicologia, até o atual interesse crescente no corpo, especialmente na teoria feminista. Os trabalhos de Eve Sedgwick e Adam Frank levaram a uma renovação do interesse em afetos e sensações corporais. A figura central aqui é a psicóloga Silvan Tomkins: “É agradável se agradar. É aterrorizante estar aterrorizado e raivoso sentir raiva. 0 afeto é válido por si mesmo, com ou sem qualquer outro referente (Sedgwick e Frank, 1995).

É isso que a dominância sônica traz à tona. Nunca se pode fazer esse prazer desaparecer totalmente, porque ele está literalmente incorporado em cada um de nós. Mas, ao mesmo tempo, ele pode ser subvalorizado, empobrecido e tornado inacessível - por razões que podem muito bem ter a ver com suas associações corporais. Isso é o que acontece quando um novo nível de mediação ou codificação é introduzido (Wilden, 1972). A gravação digital tornou a gravação analógica deficiente exatamente deste modo. O exemplo histórico desse processo é, evidentemente, o modo pelo qual a cultura letrada construiu sua supressão da cultura oral (Rotman, 1993, 2002). Nesse caso, as qualidades intrínsecas da comunicação oral, isto é, sua performance corporal, eram, a princípio, impossíveis de serem capturadas pelo novo código visual. Como resultado, ou por causa dessa falta ou inadequação, o novo código visual introduziu um novo conjunto de parâmetros - como armazenamento, reprodução e propriedade individual - 
através do qual o antigo código oral é condenado como irremediavelmente inferior. ${ }^{29}$

\section{Regimes Sensoriais Sônico e Visual}

Com a dominância sônica, o som desloca a visão como modalidade sensorial dominante. 0 valor polêmico da ideia de dominância é chamar atenção para o quão frequentemente se presume que a dominância visual é a norma consensual. Na festa de sound system de reggae, o som se torna uma coisa em si e para si mesma. Isso não é o que ocorre em um concerto ou show de palco, como se diz na Jamaica, onde a galera pode geralmente ver o artista se apresentando diante dela. Na festa, quase não há fonte, referência, localização ou origem visível do som. 0 artista que fez a gravação está presente apenas através de sua voz descorporificada. Mesmo o seletor que toca o disco está frequentemente encoberto pela escuridão. Isso permite ao som ter sua própria autonomia. 0 som é uma coisa específica na festa, mas a permeia. E isso permite que os indivíduos na galera tenham uma relação não com o som como algo separado deles, mas no som como algo que faz parte deles. Quebrar a sincronização normal entre som e imagem permite à multidão cercada pelos paredões de caixas de som, ou os caras próximos de um alto-falante, estarem literalmente dentro do som e o som, dentro deles.

A dominância sônica produzida no contexto da festa de sound system de reggae pode ser considerada como um experimento naquilo que seria um mundo governado pelo som, ou ao menos entendido em termos de uma metáfora sônica. Uma das diferenças cruciais entre o regime do ouvido, estabelecido momento a momento pela dominância sônica, e o regime do olho é que o sônico tende a adaptar-se melhor ao visual do que o visual se adapta ao sônico. Há ampla evidência disso na própria festa de sound system. Aqui, se considera que o ambiente sônico fornece o quadro ideal para o que é chamado de "desfilar" - ser visto lá, usando que roupa, com quem, e assim por diante. Além disso, o link das câmeras ao vivo a monitores de televisão e, às vezes, telas de projeção, ilustra o

Dossiê A Música e suas Determinações Materiais - https://revistaecopos.eco.ufri.br/ 
valor, para o visual, de sua integração com a experiência sônica. A festa de sound system é um ambiente multimídia e multisensorial.

De modo geral, pode-se dizer que a tradição filosófica ocidental tende a organizar os sentidos hierarquicamente, privilegiando claramente a modalidade sensorial visual como o melhor fundamento para o conhecimento. A visão e a vista formam o tropo abrangente pelo menos desde Descartes e o Iluminismo (Jay, 1993; Rorty, 1979; Jacobs, 2001). ${ }^{30}$ Uma metáfora fundadora dessa tradição é a caverna de Platão - onde as imagens sombras do mundo real são jogadas na parede. De fato, o imperativo visual é tão forte que poucos param para notar que, de longe, o fator sensorial mais contundente de qualquer caverna não é visual, mas sônico - o eco. ${ }^{31} \mathrm{~A}$ afirmação filosófica da hierarquia visual dos sentidos é bastante contraintuitiva. Mas isso não evitou que seu reflexo fosse visto em presunções cotidianas do senso comum. Cegadxs por imagens e por nossa exposição a telas, entendemos que vivemos em uma cultura visual, e não sônica.

Tendendo a ignorar a experiência, a prática cotidiana ou a operação real das modalidades sensoriais, as teorias social, literária, psicanalítica, antropológica e cultural das décadas recentes não fizeram nada além de seguir esse processo visual. Com algumas poucas exceções, como a ideia de Louis Althusser de chamar ou interpelar os sujeitos, houve uma obsessão com o Olhar e a interminável "leitura" de tudo como "texto". Consequentemente, a cultura sônica, a escuta e abordagens energéticas foram ignoradas, como, por exemplo, na conversão que Lacan faz do modelo psicodinâmico de Freud para seu próprio modelo linguístico. Como foi dito na seção de abertura, houve uma longa associação entre o visual, o racional e a mente. Isso foi distinguido do - e, de fato, oposto ao - sônico, ao irracional e ao corpo (Levin, 1985).

Contra isto, é preciso apontar que a hierarquia dos sentidos em que o visual domina, além de não ser precisa na prática, não é, de modo algum, universal. 0 modelo ocidental dos cinco sentidos, que são primariamente orientados em torno

Dossiê A Música e suas Determinações Materiais - $h$ ttps://revistaecopos.eco.ufri.br/ 


\section{DOSSIE}

da visão para favorecer a razão instrumental, nos foi legada por Aristóteles. Mas esse certamente não é o único sistema possível. Em 1883, Lord Kelvin, em seu Os Seis Caminhos Para o Conhecimento [The Six Gateways to Knowledge], dividiu o sentido do tato em sentido de calor e sentido de força (Kahn, 1999, p. 77). 0 educador e filósofo Rudolph Steiner desenvolveu um sistema sensorial duodécuplo: tato; senso de vida; auto movimento; equilíbrio; olfato; paladar; visão; senso de temperatura; audição; senso de fala; senso de conceito; e senso de ego (Soesman, 1990).

Em seu livro Culture and the Senses, a antropóloga Kathryn Linn Geurts estudou uma sociedade na qual o sentido dominante não era mesmo um dos cinco normalmente considerados como definitivos (Geurts, 2003). ${ }^{32}$ Para o povo falante de Anlo-Ewe, do sudeste de Gana, o sentido mais importante é o equilíbrio. 0 sentido de equilíbrio - físico, psicológico, espiritual e metafórico - orienta todos os outros sentidos corporais como a visão o faz na tradição filosófica ocidental. ${ }^{33}$ Geurts discute os sentidos como: "maneiras de incorporar categorias culturais, ou de internalizar ao corpo certos valores ou aspectos do ser que uma comunidade cultural específica considera, historicamente, como estimado" (itálico no original). Seria de se esperar, a partir da hipótese de Sapir-Whorf sobre os limites constituídos pela linguagem, que a importância de uma modalidade sensorial seria evidenciada pela enorme quantidade de vocabulário e isso é o que, de fato, Geurts encontrou. Certamente, eu descobri que os engenheiros do Stone Love e muitos daqueles envolvidos no modo de vida dos sistemas de som tinham um enorme vocabulário para descrever todas as nuances, filigranas, variedade de tipos, efeitos e afetos do som aos quais eles são sensitivos e sensíveis.

Mas por que importa qual é o sentido dominante ou mesmo quantos sentidos existem? Eu sugiro que isso se torna cada vez mais importante na medida em que pesquisas feministas, dentre outras, passam a levantar as questões teóricas em jogo no dualismo mente/corpo. Isso ocorre geralmente para desenvolver uma 


\section{DOSSIE}

compreensão da inteligência do corpo que desloca o tradicional privilégio da mente (Grosz, 1994; Falk, 1994; Wilson, 1998). Os processos de incorporação [embodiment] só podem ocorrer através da percepção sensorial. Enquanto o foco esteve nos processos mentais abstratos, era fácil presumir a uniformidade dos dados sensíveis originados nos diferentes sentidos. Investigar a incorporação requer uma consideração mais cuidadosa de qualidades específicas e únicas das próprias modalidades sensoriais. 0 sound system de reggae e sua produção de dominância sônica podem ser usados para explorar precisamente essa questão acerca do som. Os sentidos são muito sensíveis ao contexto. Talvez, a única distinção não contextual entre som e visão diz respeito à passagem do tempo. 0 som é baseado no tempo de um modo tal que a imagem não é (apesar de, evidentemente, o cinema repousar sobre a ilusão ótica de movimento da imagem através do tempo em um ritmo de 25 quadros por segundo). A música não pode ser tocada de trás pra frente, mas as imagens podem. 0 que é escrito - no espaço tende a manter o status quo, enquanto o que é dito - no tempo - muitas vezes o questiona.

Talvez por causa das congruências entre escutar e tocar, a modalidade sensorial sônica evoca frequentemente associações emocionais de um modo tal que as meras imagens não conseguem. Os sons evocam imagens mais do que as imagens evocam sons. Os executivos de publicidade que conectam seus produtos às nossas memórias musicais íntimas exploraram consistentemente essa tendência sensorial, como o fez Nick Hornby em seus bem-sucedidos livros Alta Fidelidade e 31 Canções. A música e o ritual são primos próximos, como foi descrito em inúmeros estudos antropológicos e, mais recentemente, na sociologia de Michel Maffesoli (1996). Ver e ouvir funcionam de modos diferentes. Como afirmou Marcel Duchamp: "Pode-se olhar o olhar; não se pode ouvir o ouvir."

Certamente, na prática, as outras modalidades sensoriais são geralmente consideradas como possuindo qualidades específicas e únicas. 0 paladar, por 
exemplo, foi considerado o mais abrangente dos sentidos. Há mais de 500 anos, se pensa que o "bom" ou "mau" gosto das pessoas as define. Etimologicamente, a palavra em inglês taste deriva de taster, do francês antigo, tendo um sentido mais corporificado de "sentir, manusear ou tocar" (Stoller, 1989, p. 23-24). De modo congruente a essas origens, o paladar (taste) é entendido fisiologicamente como o mais "primitivo" dos sentidos, com os nervos dos sensores de sabor indo diretamente ao hipocampo, que é filogenicamente a parte mais antiga do cérebro. Em seu monumental Em busca do tempo perdido, Marcel Proust explora o fato que o gosto do madeleine deslancha sentimentos e associações longamente esquecidos pelo cérebro mais avançado, consciente e racional.

Também as várias capacidades e sensibilidades dos diferentes modos sensoriais estão sendo cada vez mais reconhecidas nas novas ciências, onde a "audificação" ou "sonificação" vem se mostrando um caminho muito mais revelador de compreensão de dados complexos do que a mais convencional visualização. Um exemplo disso é o trabalho de Florian Dombois (2001) sobre terremotos. Sua áudio-sismologia permite uma compreensão muito mais precisa desses fenômenos do que qualquer representação visual. De fato, a audição é frequentemente considerada capaz de reconhecer relações proporcionais muito melhor do que a visão. 0 reconhecimento da oitava musical foi identificada através do mais amplo leque de culturas. ${ }^{34}$

Novamente, se nos voltarmos à prática real, qualquer ideia de hierarquia filosófica ou competição entre modalidades sensoriais se dissolve em combinação, cooperação e ampliação. Em vez do domínio de um sentido, ou de qualquer hierarquia de sentidos, na prática há muito mais uma matriz de sentidos, ou fluxo, ou teia de sentidos cujas prioridades variam de acordo com o contexto. A qualquer momento, trata-se de uma impressão multisensorial do mundo, da qual um entendimento completo depende. ${ }^{35}$ Portanto, minha ênfase no som na dominância sônica não implica em nenhuma ambição de substituir uma hierarquia visual por 
uma sonora. Enquanto tal separação pode ser esperada da lógica binária ou/ou [either/or] da dominação visual, simplesmente não é o que ocorre no "raciocínio" "um ou outro e ambos" - conforme a filosofia Rastafari jamaicana - do sônico. Diferentemente da hierarquia da dominação visual que tende a ganhar o crédito pela informação recebida através dos outros sentidos, o sônico tende a respeitar cada sentido específico.

\section{Transdução e Corporificação Sônica}

Na festa de sound system de reggae, a dominância sônica amplifica os prazeres do som. Até aqui, esses prazeres foram descritos em termos de como o som faz "uma ou outra e ambas" as conexões: com nós mesmxs, por meio da própria sensação; com outras pessoas, na dança; com o visual e outras modalidades sensoriais do evento; e com os múltiplos tempos, espaços e tradições do dancehall. E, baseado nisso, a dominância sônica produz mais um tipo de conexão, não horizontalmente, mas verticalmente ao "nível maior", como se diria na Jamaica. Se a dominância sônica é a iminência do som, essa conexão é a transcendência.

Sugerir que a galera de dancehall é atraída por algum tipo de experiência quase espiritual implica em dizer que a festa de sound system tem certas características em comum com cultos da Igreja Batista Jamaicana e rituais espirituais de matriz africana. Embora isso seja verdade, eu gostaria de ir além na compreensão dos processos e mecanismos por meio dos quais esse tipo de transformação acontece. Para fazê-lo, vou descrever a dominância sônica da festa de sound system como produtora do que pode ser chamado de "transdução". É possível que este processo de transdução seja aquilo que gera o prazer, a alegria e o excesso pelos quais o dancehall é famoso.

A festa de sound system de reggae oferece vários exemplos de transdução. A transdução, na física, é o processo pelo qual uma energia se transforma em outra 
de natureza diferente. ${ }^{36} \mathrm{Um}$ exemplo de transdutor, sem o qual nenhum sistema de som poderia funcionar, é o alto-falante. Engenheiros prontamente descrevem o alto-falante como um transdutor. Com uma caixa de som, isso significa transfigurar ondas eletromagnéticas, sobre as quais o amplificador opera, em ondas sonoras que podemos ouvir. Como Horace McNeal, engenheiro chefe e construtor do sound system Stone Love, me explicou, isso é feito através da bobina eletromagnética que movimenta o diafragma do falante. Outro exemplo de transdutor é um microfone simplesmente um falante ao contrário. Nele, as ondas sonoras são convertidas em ondas eletromagnéticas para amplificação, etc. No contexto da festa de sound system de reggae, como era de esperar, o DJ usa um microfone para se dirigir à plateia e "construir a vibe".

0 terceiro exemplo de transdução não diz respeito a fluxos eletromagnéticos, mas a correntes corporais. 0 corpo humano pode ser considerado um transdutor sensório - na dança. Em um nível mais simples, uma linha de baixo provoca o movimento cinético de bater o pé no ritmo. Isso ocorre automaticamente, sem pensar, como uma resposta mais corporal do que racional. É uma transformação de energia sônica em energia cinética. A festa de sound system de reggae é um aparato social e cultural altamente elaborado que informa e modela esse movimento na forma da dança da moda corrente. Os dois lados do sônico, o etéreo e o material, são amplificados pela tradição e pela tecnologia, respectivamente. Esse rico e instigante mundo da dança da festa de sound system merece ter suas próprias pesquisa e análise. ${ }^{37}$ Vou apenas dar uma ideia de como é a dança:

“...mais dramática é a dança Drive By, na qual os homens se inclinam pra trás, como se estivessem em um carro, e colocam as mãos no ar, como se segurassem o volante, dirigindo, com os limpadores de pára-brisa sendo rugidos no momento certo por DJ Skyjuice. Uma formação de cinco ou seis dançarinos então varre toda a extensão da arena, seguida pela câmera de vídeo e seu refletor de luz, circulada pelo círculo movente da galera..."38 
Devido às suas associações corporais inevitáveis e ao fato de que um senso de movimento não é um dos cinco sentidos privilegiados, não deveria ser nenhuma surpresa que a dança, e particularmente a dança africana, seja tão frequentemente reduzida e biologizada como sendo um "ritmo natural". Como um contraargumento, a fenomenologia de Merleau-Ponty enfatiza que, sem motilidade, esse potencial para o movimento, o mundo não faria sentido nem teria profundidade (Merleau-Ponty, 1962). Meu uso do termo transdução, como uma conexão ou homologia entre os circuitos físico e social, fluxos e campos, não tem a intenção de funcionar como um reducionismo. De outro modo, tenta abrir as possibilidades imaginativas e científicas - inspirando-se, por exemplo, na aplicação por Norbert Wiener dos princípios de feedback mecânicos aos comportamentos humanos. Foi o que deu à luz à nova ciência da cibernética (Wiener, 1950).

Este conceito de transdução exemplifica, mais uma vez, como a condição de dominância sônica pode revelar o funcionamento muitas vezes oculto dos sentidos. A cada ponto de transdução eletromagnética, sônica ou cultural, uma coisa se transforma na outra. Isso cria um excedente. A transdução descreve um processo de transcendência das dualidades de forma/conteúdo, padrão/substância, corpo/mente e matéria/espírito. Um transdutor é um dispositivo para alcançar a velocidade de fuga para deixar o mundo do ou/ou e entrar o mundo de uma ou outra e ambas. Ele aumenta a velocidade e energia, do mesmo modo que o sound system de reggae amplifica o som.

A dominância sônica transduz a galera através de vários limiares ao longo da festa, até o amanhecer. Ela gera um tipo de ambiente e experiência muito especial - um lugar entre lugares e um tempo fora do tempo. 0 antropólogo Victor Turner (1974) os descreve como lugares ou estados "liminares". Fora da sociedade normal, esses são limiares nos quais ocorrem transições, transfigurações e ritos de passagem. ${ }^{39}$ Em tais estados liminares, a comunicação frequentemente acontece em um nível sublime ou elevado e em uma língua não mundana, como o falar em

Dossiê A Música e suas Determinações Materiais - https://revistaecopos.eco.ufri.br/ 


\section{DOSSIE}

línguas que ocorre entre pentecostais, comum nas igrejas jamaicanas. ${ }^{40}$ Talvez a música forneça uma língua etérea semelhante. Como foi dito acerca da privação sensória, estado liminares de sobrecarga têm efeitos e afetos semelhantes. Períodos de isolamento, sofrimento e provação são invariavelmente os prérequisitos para o renascimento de um líder em seu novo papel, de acordo com a maior parte dos credos religiosos. Com os extremos do excesso e da privação, parece que ocorre um processo de dessensibilização e sensibilização, uma ou outra e ambas.

Como estado liminar, a festa de sound system fornece ampla evidência de muitos dos papeis, figuras e práticas comuns às mitologias tanto ocidentais como africanas. Limiares tradicionalmente exigem guardiões. No mundo do sound system de reggae, esse papel cai nas mãos do porteiro [Gateman] que controla não apenas a entrada na festa, mas também está no comando da segurança do lado de dentro do local. Como Cérbero, o cachorro com três cabeças e rabo de serpente na entrada do submundo mitológico grego do Hades, o papel do porteiro é desafiar e testar aqueles que desejam cruzar o limiar.

E qualquer cruzamento como esse requer um guia para oferecer a esperança de um jornada de volta tranquila. Na festa de sound system de reggae, esse papel é assumido pelo seletor que escolhe as gravações a serem encaixadas no clima e na vibe da galera e pelo DJ que lhe dá um feedback verbal e a anima. A festa de sound system compartilha certas características com as tradições africanas antigas. 0 feedback de chamada-e-resposta entre o DJ e a galera, por exemplo, que também existe nas igrejas batistas jamaicanas, conecta os papeis do DJ e do pastor para muitos na galera do dancehall. O DJ guia suas jornadas transformadoras através da noite e assegura uma re-entrada pacífica e segura no mundo normal pela manhã. Muitas vezes se diz que o DJ, sentindo a vibe da galera e da música, está "montando o ritmo" ["riding the riddem"], combinando perfeitamente suas palavras e seu conteúdo com a batida. Na festa de sound system de reggae, é o DJ

Dossiê A Música e suas Determinações Materiais - https://revistaecopos.eco.ufrj.br/ 


\section{DOSSIE}

que está no controle, ele ou ela monta o espírito nas correntes da música. Isto, na verdade, transpõe a ideia comum de possessão espiritual, como no Vodu, onde os possuídos são os "cavalos" dos deuses.

Outro exemplo de um deus guardião é Legba, o deus das encruzilhadas na África Ocidental (Brown, 1947 e 1969; Bakare-Yusuf e Weate, 2004). ${ }^{41} 0$ folclore caribenho renomeia esse deus trapaceiro como Ananse, que toma a forma de uma aranha, sentando-se no meio de sua teia. Para os gregos, o deus da transformação e da comunicação é Hermes, para os romanos, Mercúrio. Invariavelmente, as encruzilhadas são os locais dessas estranhas transformações: onde Édipo matou seu pai; onde as bruxas de Macbeth se encontram; e onde Robert Johnson nos diz que vendeu sua alma ao diabo em troca do blues. Essas correntes correm profundamente abaixo da consciência normal do pensamento racional.

A dominância sônica da festa de sound system de reggae gera seu próprio estado de ser, sua própria lógica específica e sua forma de racionalidade distinta e diferente. A lógica aristotélica tradicional, que é considerada a norma racional, renega a contradição. ${ }^{42}$ Ela estabelece que A e não A não podem ser verdadeiros ao mesmo tempo. Mas as galeras do dancehall estão repletas de exemplos da lógica "um, outro e ambos". A cultura dancehall prontamente abraça tais contradições aparentes. Muitas vezes, letras negativas "gangsta" aparecem de um lado e as edificantes letras positivas e "culturais" do outro lado do mesmo single de vinil 7 polegadas, $45 \mathrm{rpm}$ (que ainda é a moeda corrente no mercado musical jamaicano). Um engenheiro de sound systems com quem eu falei que se dispôs a me explicar como transdutores funcionam a partir de um diploma de graduação em engenharia eletrônica, também estava confortável em usar a palavra "ciência" no sentido jamaicano coloquial de mágica, Obeah ou Vodu. De fato, na dança do Stone Love, uma vez que todos os equipamentos foram ajustados e testados, o engenheiro tira a poeira de todos os knobs de controle com um pincel e mandava limpar o interior de cada uma das caixas de som com água e sabão. Mais pesquisa é necessária, mas 


\section{DOSSIE}

isso pode ser considerado um ritual ou uma limpeza espiritual - para complementar a pureza do som. ${ }^{43}$

Isso nos leva a uma área de pesquisa substancial no que diz respeito às relações entre tecnologia e tradição e, de fato, entre tecnologia e magia. ${ }^{44}$ Particularmente relevante aqui é a tese central de Jamais fomos modernos, de Bruno Latour (1993), isto é, que o moderno e o antigo sempre coexistiram no sentido de que a cidade mediana mistura prédios de diferentes períodos e estilos históricos. Latour vai além da ideia de Walter Benjamin de que o modernismo envolve um retorno do reprimido do "primitivo" (Taussig, 1993). Estendendo a abordagem antidesenvolvimentista de Latour, eu sugeriria: nós sempre fomos modernos, modernos e antigos, um ou outro e ambos. A festa de sound system de reggae é uma evidência disso. Assim como ela é um aparato diaspórico - diferentes lugares no mesmo tempo, é também um aparato sincrético - diferentes tempos em um mesmo lugar. Ao observar uma "obrigação" ou cerimônia kumina jamaicano, o que literalmente me atingiu de modo mais poderoso foi o baque do ar vindo do toque dos tambores. Isso me fez perceber que se a bobina eletromagnética, contra o diafragma do alto-falante, se torna um transdutor, então do mesmo modo o faz a mão mecânica contra a pele animal. ${ }^{45}$

Tanto os aspectos materiais quanto os etéreos do som nos conectam íntima e evidentemente ao nosso corpo. Sensação, sensibilidade e sensualidade são todas experiências corporais. A carne exposta, os fios-dentais e as "impressoras de boceta" da moda dancehall, que tanto escandalizam as classes médias jamaicanas, não fazem nada a não ser celebrar o corpo feminino. A dominância sônica engendra esse corpo - criando-o e sexando-o. Assim como Freud descreveu os sonhos para o inconsciente, eu gostaria de chamar o sônica de "a estrada real" para o corpo, o corpo sônico, o corpo tocado pelo som. Trata-se de um corpo ressonante, específico, compartilhado, social, imediato e carnudo. O termo "corpo sônico" implica tanto o corpo do som como o som do corpo, um ou outro e ambos. A corporalidade do corpo sônico se expressa no som e faz sua performance por meio

Dossiê A Música e suas Determinações Materiais - https://revistaecopos.eco.ufri.br/ 
do som. Nós podemos escutar o corpo sônico tanto pelos sintomas, como com um estetoscópio médico no peito, por simpatia, com nossos corações abertos à sua música. Escutar nos coloca dentro e fora de nós mesmxs. Ao escutar o sound system de reggae, talvez seja possível entender sua racionalidade sônica. E isso poderia funcionar como modelo para o nosso pensamento em outros lugares. Como afirmou David Levin: "Através do desenvolvimento da nossa escuta, talvez nos seja dado um senso de uma norma diferente, uma medida diferente, um princípio diferente para pensar o "ratio" da racionalidade (Levin, 1989, p. 33).

\section{Referências bibliográficas}

Abram, D. (1996) The Spell of the Sensuous. London: Random House.

Attali, J. (1985), Noise: The Political Economy of Music. Manchester: Manchester University Press.

Augé, M. and Howe, J. (1995) Non-Places: Introduction to and Anthropology of Super Modernity. London: Verso.

Bakare-Yusuf, B. (2001), 'The Sea of Memory; Embodiment and Agency'. In: The Black Diaspora, Tese de doutorado, Faculty of Social Sciences, University of Warwick.

Bakare-Yusuf, B. and Weate, J. (2004), Ojuelegba: The Sacred Profanities of a West African Crossroad. In: Salm, S. and Falola, T. (orgs.). African Urban Cultures. Durham: Carolina Academic Press.

Barthes, R. (1977), 'The Grain of the Voice'. In: Music, Image, Text. London: Fontana.

Bataille, G. (1988), The Accursed Share. New York: Zone Books.

Bausinger, H. (1961, 1990), Folk Culture in a World of Technology. Bloomington, IN: Indiana University Press.

Blackman, L. (2001), Hearing Voices: Embodiment and Experience. London: Free Association.

Bourdieu, P. (1977), Outline of a Theory of Practice. Cambridge: Cambridge University Press.

Bradley, L. (2000), Bass Culture : When Reggae Was King. London: Viking.

Braidotti, R. (1994), Nomadic Subiects. New York: Columbia University Press.

Brown, N. O. (1947, 1969), Hermes the Thief: The Evolution of a Myth. New York: Vantage Books.

Dossiê A Música e suas Determinações Materiais - $h$ ttps://revistaecopos.eco.ufri.br/ 
Casey, E. S. (1993), Getting Back into Place: Toward a Renewed Understanding of the Place-World. Bloomington, IN: Indiana University Press.

Chernoff, J. M. (1979), African Rhythm and African Sensibility: Aesthetics and Social Action in African Musical Idioms. Chicago: Chicago University Press.

Chude-Sokei, L. (1994), '"Dr Satan's Echo Chamber: Reggae, Technology and the Diaspora Process', Bob Marley Lecture, Institute of Caribbean Studies, Reggae Studies Unit, University of the West Indies.

Cooper C. (1993), Noises in the Blood: Orality, Gender and the 'Vulgar' Body of Jamaican Popular Culture. London: Macmillan.

Cooper, C. (1994), "'Lyical Gun"; Metaphor and Role Play in Jamaican Dancehall Culture', The Massachusetts Review, Autumn-Winter.

Crary, J. (1993), The Techniques of the Observer. Cambridge MA: MIT Press.

Crary, J. (2001), The Suspension of Perception: Attention, Spectacle and Modern Culture. Cambridge, MA: MIT Press.

Cruz, J. (1999), Culutre on the Margins: The Black Spiritual and the Rise of American Cultural Interpretation. Princeton: Princeton University Press.

Davis, E. (1998), TechGnosis: Myth, Magic and Mysticism in the Age of Information. London: Serpents Tail.

Davis, E. (1999), "Roots and Wires": Polyrhythmic Cyberspace and the Black Electronic'. http://www.levity.com/figment/cybercont.html.

Deleuze, G. (1985b), Cinema 2. The Time Image. London: Athlone press.

Deleuze, G. (1986a), Cinema 1. The Movement Image. London: Athlone Press.

Deleuze, G. (1993), The Fold, Leibniz and the Baroque. London: Athlone Press.

Deleuze, G. and Guattari, F. (1989), A Thousand Plateaux: Capitalism and Schizophrenia. London: Athlone Press.

Domblais, F. (2001), 'Using Audification in Planetary Seismology', In: Proceedings of the 2001 International Conference on Auditory Display, Espoo, Finland, 29 July - 1 August 2001 (see also http://www.gmd.de/projects/auditory seismology/).

Eshun, Kodwo (1998), More Brilliant Than the Sun: Adventures in Sonic Fiction. London: Quartet.

Falk, P. (1994), The Consuming Body. London: Sage.

Fechner, G. T. (1966), Elements of psychoptrysics, Vol.1, New York: Holt, Rinehart \& Winston.

Gaillot, M. (undated, circa 2000), Multiple Meaning: Techno - an artistic and political laboratory of the present, Paris: Editions Dis Voir.

Dossiê A Música e suas Determinações Materiais - https://revistaecopos.eco.ufri.br/ 
Geults, K. L. (2003), Culture of the Senses: Bodily Ways of Knowing in an African Community. Berkeley CA; California University Press.'

Grorsz, E. (1994), Volatile Bodies: Towards Corporeal Feminism. Bloomington: Indiana University press.

Hardt, M. and Negri, A. (1994), Labor of Dionysus: A Critique of the State-Form, Minneapolis: University of Minnesota Press.

Hardt, M. and Negri, A. (2000), Empire, Cambridge MA: Harvard University Press.

Hebdige, D. (1979), Subculture: The Meaning of Style, London: Methuen.

Henriques, F. (1953), Family and Colour in Jamaica. London: Eyre \& Spottiswoode.

Henriques, J. (2002a). "'Sonic" Scriptwriting: Writing memorable movies', Scriptwriter, Issue 3, March.

Henriques, J. (2002b), 'Thinking without Trace', Journal of Visual Culture, 1(3): 355-8.

Henriques, J., Hollway, W, Urwin, C., Venn, C. and Walkerdine, V. $(1984,1998)$, Changing the Subject: Psychology, Social Regulation and Subjectivity. London: Routledge.

Howe, D. (org.) (1977) The Road Mek to Walk on Carnival Day: The Battle for the West Indian Carnival in Britain. London: Race Today Publications.

Hurtston, Z.N. (1934), 'Characteristics of Negro Expression'. In: Cunard, N. (org.). Negro. London: Lawrence \& Wishart.

Ivins, W. M. Jr. $(1938,1975)$ On the Rationalization of Sight. New York: Da Capo.

Jacobs, K. (2001), The Eye's Mind: Literary Modernism and Visual Culture. Ithaca: Cornell University Press.

Jay, Martin (1993), Downcast Eyes. Berkeley: University of California Press.

Kahn, D. (1999). Noise Water Meat: A History of Sound in the Arts. Cambridge MA: MIT Press.

Kittler, F. A. (1999), Gramophone, Film, Typewriter. Stanford: Stanford University Press.

Latour, B. (1990), 'Drawing Things Together'. In: Lynch. M. and Woolgar, S. Representation in Scientific Practice, Cambridge MA: MIT Press, pp. 19-68.

Latour, B. (1993), We Have Never Been Modern. Harlow: Pearson.

Lawlor, R. (1982), Sacred Geometry. London: Thames \& Hudson.

Levin, D. M. (1985), The Body's Recollection of Being: Phenomenological Psychology and the Deconstruction of Nihilism. London: Routledge and Kegan Paul.

Levin, D. M. (1988), The Opening of Vision. London: Routledge. 
Levin, D. M. (1989), The Listening Self: Personal Growth, Social Change and the Closure of Metaphysics. London: Routledge.

Lord, A. B. (1960, 2000), The Singer of Tales. Cambridge: Cambridge University Press.

MacKenzie, A. (2002), Transduction: Bodies and Machines at Speed. London: Continuum.

Maffesoli, M. (1996), The Time of the Tribes: The Decline of Individualism in Mass Society. London: Sage.

Merleau-Ponty, M. (1962), The Phenomenology of Perception. London: Routledge and Kegan Paul.

Moore, A. (2003), 'Membranes in Space and the Transmitting Ear', Cybersonica '03, London: Cybersalon, p. 5-9,

Ree, J. (1999), I see a Voice: A Philosaphical History af Language, Deafness and the Senses. London: HarperCollins.

Romanyshyn, R. D. (1989), Technology as Symptom and Dream. London: Routledge.

Rorty, R. (1979), Philosophy and the Mirror of Nature. Princeton, NJ: Princeton University Press.

Rotman, B. (1993), Ad Infinitum: The Ghost in Turing's Machine - Taking God Out of Mathematics and Putting the Body Back In. Berkeley, CA: Stanford University Press.

Rotman, B.(2002),'The Alphabetic Body', Parallax, 8(1): 92-104.

Ryman, Cheryl (1984), 'Kumina - Stability and Change', The African Caribbean Institute of Jamaica Research Review, 1, 81-128.

Salewicz, C. and Boot, A. (2001), Reggae Explosion: The Story of Jamaican Music, London: Virgin Publishing.

Scarry, E. (1985), The Body in Pain: The Making and Unmaking of the World. Oxford: Oxford University Press.

Schafer, R.M. (1977), The Tuning of the World. New York: Alfred A. Knopf.

Sedgwick, E. K. and Frank, A. (1995), Shame and its Sisters: a Silvan Tomkins Reader. Durham: Duke University Press.

Serres, Michel (1982), The Parasite. Baltimore: Johns Hopkins University Press.

Soesman, Albert (1990), Our Twelve Senses. Stroud: Hawthorne Press.

Somé, M. P. (1994), Of Water and the Spirit: Ritual, Magic and Initiation in the Life of an African Shaman. New York: Penguin Arkana.

Sto1ler, P. (1989), The Taste of Ethnographic Things: the Senses in Anthropology. Philadelphia, PA: University of Pennsylvania Press.

Stolzoff, N. C. (2000), Wake the Town and Tell the People. Durham: Duke University Press.

Dossiê A Música e suas Determinações Materiais - https://revistaecopos.eco.ufri.br/ 
Taussig, M . (1993), Mimesis and Alterity: A Particular History of the Senses. London: Routledge.

Turner, V. (1974), Dramas, Fields and Metaphors. Ithaca: Cornell University Press.

White, G. (1984), 'The Development of Jamaican Popular Music part 2', The African Caribbean Institute of Jamaica Research Review 1, 47-80.

Wiener, N. (1950), The Human Use of Human Beings. New York: Anchor.

Wilden, A. (1972), System and Structure: Essays in Communication and Exchange. London: Tavistock Anthony.

Williams D.C . (1955), 'Acoustic Space'. Explorations, (February): 15-20.

Wilson, E. A. (1998), Neural Geographies: Feminism and the Microstructure of Cognition. London: Routledge.

Zimmerman, M. E. (1990), Heidegger's Confrontation with Modernity: Technology, Politics, Art. Bloomington, IN: Indiana University Press.

${ }^{1}$ Ideias são seres conversacionais, e a dialógica é a única lógica nesse sentido. O ímpeto para minha presente pesquisa surgiu de uma conversa com Stuart Hall. Eu também gostaria de agradecer aos meus colegas da Goldsmiths College, John Hutnyk, David Morley e Keith Negus pelos seus comentários proveitosos dos primeiros rascunhos. Meus agradecimentos também a Bibi Bakare-Yusuf por suas generosas sugestões.

${ }^{2}$ O trabalho referência sobre paisagens acústicas é o de Schafer (1977). Para uma abordagem pioneira ao pensamento no e com o som, cf. Eshun (1998).

${ }^{3}$ Ver, por exemplo, Gaillot (c. 2000).

${ }^{4}$ Minha pesquisa mais recente foi feita com o Stone Love, mas já trabalhei com outros sound systems no Reino Unido: O Saxon Sound, no filme Ragamuffin, e o JB International, no longa Babymother.

${ }^{5}$ Para uma descrição acessível da importância dos sentidos que é, ao mesmo tempo, fenomenológica e xamanística, ver Abram (1996).

${ }^{6} \mathrm{Eu}$ preciso agradecer a Bibi Bakare-Yusuf por enfatizar esse último para mim e em sua própria pesquisa sobre o dancehall.

7 Ao investigar os extremos sensoriais da dominância sônica, um benefício de se usar um aparato já constituído social e culturalmente é que o costume e a prática oferecem uma melhor garantia de segurança do que as condições laboratoriais criadas artificialmente poderiam fazer.

${ }^{8}$ Existem várias outras abordagens da cultura reggae e dancehall, como o estudo pioneiro de Carolyn Cooper (1993) sobre a cultura dancehall. Outras abordagens concentraram-se na investigação antropológica e sociológica: Stolzoff (2000) e Bradley (2000). Outro foco de pesquisa tem sido a letra, ver, por exemplo: Cooper (1994). Um dos poucos a investigar o aspecto sonoro do sound system é ChudeSokei (1997). A imagem e a música do reggae são bem abordadas em Salewicz e Boot (2001). Para uma abordagem única e fenomenologicamente informada do dancehall, consultar Bakare-Yusuf (2001). Hebdige (1979) foi o primeiro a considerar os aspectos sônicos do sound system enquanto tal.

${ }^{9}$ Para o relato antropológico mais abrangente de kumina e outras cerimônias jamaicanas, consulte Ryman (1984) e, por sua influência na música reggae, White (1984).

${ }^{10}$ Em outros contextos, como na festa de sound system, a modalidade sensorial visual também é usada para fornecer orientação sensorial, foco e amplificação. Exemplos de tais aparelhos em outros campos incluem o design da prisão de panópticos de Bentham e o teatro de anatomia de 1609 de Leiden. Como sugerirei abaixo, uma das funções críticas que a dominância sônica facilita é um tipo particular de transformação. A esse respeito, a festa de sound system de reggae pode ser considerada como um aparelho semelhante a um laboratório alquímico.

Dossiê A Música e suas Determinações Materiais - https://revistaecopos.eco.ufri.br/

ISSN 2175-8689 - v. 23, n. 1, 2020

DOI: 10.29146/eco-pos.v23i1.27543 
${ }^{11}$ Ver, por exemplo, os primeiros estudos de meu pai sobre essas questões: Henriques (1953).

${ }^{12}$ Como explorarei em pesquisas posteriores, a dominância sônica é alcançada através de certas operações tecnológicas. A principal delas é a separação de diferentes frequências de som através de portas e filtros e a combinação delas na configuração das pilhas de alto-falantes e no "mix" definido pelos controles do pré-amplificador.

${ }^{13}$ Para uma discussão evocativa e provocativa dessa ideia de interrupção, ver Serres (1982).

${ }^{14}$ Veja especialmente o capítulo 2, Barreira de Som e Gerenciamento de Som, em Cruz e Jon (1999: 45).

${ }^{15}$ As experiências mais detalhadas foram conduzidas por D.O. Hebb na Universidade McGill, Montreal, Canadá, em 1958.

16 Esse estado "super liminal" pode ser contrastado com os estados subliminares identificados pela primeira vez por Vance Packard (1957), que descreveu como as mensagens de publicidade de produtos são sugeridas a potenciais compradores abaixo do nível de consciência.

17 E cem anos depois esse interesse foi transfigurado na medida quantitativa da diferença entre o psicológico e o social na Psicologia Social Européia e na teoria da Categorização Social. Veja minha crítica a isso em Henriques et al. (1984, 1998).

${ }^{18}$ Para a discussão mais estimulante da relação entre dor e criatividade da imaginação, ver Scarry (1985

${ }^{19}$ Entrevista com Horace McNeal, construtor de falantes e engenheiro-chefe da Stone Love, Jones Town, Kingston, 26 de julho de 2002.

${ }^{20}$ D.C. Williams foi um dos colaboradores de Marshall McLuhan na década de 1950.

${ }^{21}$ Lembro-me de uma das minhas inspirações para esta peça no prólogo de Ralph Ellison para $O$ Homem Invisível. Ele descreve $O$ Homem Invisível vivendo no subsolo: “Agora eu tenho um rádio-fonógrafo; eu pretendo ter cinco. Há uma certa morte acústica no meu buraco, e quando tenho música, quero sentir sua vibração, não apenas com meus ouvidos, mas com todo o meu corpo. Eu gostaria de ouvir cinco gravações de Louis Armstrong tocando e cantando 'What Did I Do to Be so Black and Blue' - tudo ao mesmo tempo". (ênfase no original).

${ }^{22}$ A distinção espaço e lugar é importante, ver Casey (1993).

${ }^{23}$ Deleuze e Guattari discutem a hecceidade em relação à sua distinção entre espaços racionalizados e não racionalizados no capítulo 14 de Deleuze e Guattari (1988).

${ }^{24} \mathrm{Eu}$ explorei essa ideia de espaço / tempo do filme, que é de fato o espaço dos sonhos no qual todo público de cinema entra, no meu drama de dança Exit no Exit, com ações repetidas, mudanças de velocidade e movimentos reversos. Minha inspiração foi o filme Choreography for the Camera, de Maya Deren. Ver também Henriques (2002).

${ }^{25}$ Alguns dos artistas atualmente gravando esses ritmos que eu particularmente gosto são Elephant Man e o grupo T.O.K.

${ }^{26}$ Palestra de Anthony Moore, "Membranes in Space and the Transmitting Ear", Goldsmiths College, 20 de março de 2003. Ver também Moore (2003).

27 Ver também Taussig (1993) e, sobre a importância da materialidade do meio de comunicação, Crary (1993, 2001). A relação entre falante e ouvinte também é explorada em relação à audição de vozes que não existem em Blackman (2001). Ver também Ree (1999).

${ }^{28}$ Apresentação de David Rodowick, Escola de Estudos Avançados da Universidade de Londres,

Simpósios de Estudos de Tela, 14 de fevereiro de 2003.

${ }^{29}$ Nos anos 50, ao investigar as origens cantadas da Ilíada e da Odisseia de Homero, Alfred Lord registrou e analisou a tradição épica eslava contemporânea cantada na Iugoslávia. Ele escreveu: "A verdade é que nosso conceito de 'o original da música' simplesmente não faz sentido nas tradições orais. Para nós, parece tão básico, tão lógico, uma vez que somos criados em uma sociedade em que a escrita fixou a norma de uma primeira criação estável na arte, que sentimos que deve haver um 'original' para tudo. O primeiro canto de uma tradição oral não coincide com esse conceito de 'original'. Precisamos enfrentar o fato de estarmos em um mundo diferente de pensamento, cujo padrão nem sempre se encaixa nos termos que gostamos de usar. Na tradição oral, a ideia de um original é ilógica... Nosso maior erro é tentar tornar 'cientificamente' rígido um fenômeno que é fluido... ”(Lord, 1960, 2000).

Dossiê A Música e suas Determinações Materiais - https://revistaecopos.eco.ufri.br/

ISSN 2175-8689 - v. 23, n. 1, 2020

DOI: 10.29146/eco-pos.v23i1.27543 
${ }^{30}$ Para uma exploração fenomenológica do sentido visual, ver Levin $(1985,1988)$.

${ }^{31}$ Meus agradecimentos a Nigel Helyer (também conhecido como Dr. Sonique) por levantar essa questão em sua fala na School of Sound Conference, Londres, em 23 de abril de 2003.

${ }^{32}$ Outro relato muito interessante dos sentidos pode ser encontrado em Stroller (1989).

${ }^{33}$ A importância desse senso de equilíbrio continua através da diáspora africana nas Américas, com o sentido do significado especial da dança, movimento e, mais geralmente, do estilo na cultura jamaicana do dancehall e talvez também esteja sendo expressos pela frase "walk the talk", que significa cumprir intenções declaradas. Ver também Hurtston (1934).

${ }^{34}$ Frederick Kittler levantou esse ponto em sua palestra na Goldsmiths College em 6 de março de 2003.

Ver também Lawlor (1982: 13).

${ }^{35}$ Além disso, cada modalidade sensorial não é tão discreta e separada das outras como é frequentemente assumido. Na prática, a sinestesia é uma ocorrência comum, certamente na linguagem cotidiana dos sentidos. Esta última está cheia de metáforas mistas de cores "quentes" ou "altas" [loud] e sons "brilhantes" ou "quebradiços". Qualidades de um sentido são prontamente transpostas para outro, ver Abram (1996) para um relato revelador disso. Além disso, os sentidos não são singulares, são bifurcados. Temos audição estereofônica e visão binocular para dar a dimensão adicional de "profundidade" a esses campos sensoriais.

${ }^{36}$ Nesse sentido, a transdução pode estar relacionada a outros tipos de mudança qualitativa, como a mudança de fase (entre sólido, líquido e gasoso); na biologia celular, serve para descrever a passagem de produtos químicos através da membrana semipermeável da parede celular; e a ideia de Malcolm Gladwell do "ponto de inflexão", em que incrementos contínuos (por exemplo, nas vendas de produtos) produzem repentinamente o resultado inovador ou descontínuo de "estar em toda parte". Para um relato filosófico de transdução baseado no trabalho de Simondon, ver MacKenzie (2002).

${ }^{37}$ L'Antoinette Osunide Stines, a coreógrafa do meu filme Babymother, sempre me ajudou a perseguir o meu interesse pela dança do dancehall. Muito pouco foi publicado sobre a dança jamaicana, mas ver o Capítulo 5 em Bakare-Yusuf (2001). Da literatura sobre dança africana, o relato mais revelador é Chernoff (1979).

${ }^{38}$ Retirado de minhas notas de campo das danças dos sistemas de som Stone Love, Metro Media, Venus Love e Young Fresh. Stakeland, Half Way Tree, Kingston, sábado, 17 de agosto de 2002, às 4h30.

${ }^{39}$ Para um dos relatos mais vívidos de tais ritos de iniciação, ver Somé (1994).

${ }^{40}$ Michel Serres fornece um relato interessante do ponto de vista da teoria da comunicação em Serres (1982).

${ }^{41}$ Ver Brown $(1947,1969)$ e Bakare-Yusuf e Weate (2004).

${ }^{42}$ Alfred Korzybski desenvolveu uma lógica não aristotélica na década de 1930. Seu famoso slogan era: "O mapa não é o território". Essa ideia de uma lógica que abraça a contradição também é apontada na ideia de Freud de que o inconsciente opera antes das marcações avaliativas conscientes de bom e ruim.

${ }^{43}$ Isso seria apoiado pela observação que também fiz dos comerciantes do mercado jamaicano que limpavam ritualmente o campo com limas e ervas antes de arrumar suas mercadorias. Eles me disseram que era para trazer um bom dia de negociação.

${ }^{44}$ Para um relato bastante acessível, leia Davis (1998). Ver também Bausinger (1961, 1990) e Zimmerman (1990).

${ }^{45}$ Sou grato a L'Antoinette Stines e ao rei kumina Oliver por me levarem a testemunhar esse "trabalho" kumina em uma recente viagem de pesquisa na Jamaica.

Dossiê A Música e suas Determinações Materiais - https://revistaecopos.eco.ufri.br/

ISSN 2175-8689 - v. 23, n. 1, 2020

DOI: 10.29146/eco-pos.v23i1.27543 